\title{
Examining the Interaction of Extroversion and Network Structure in the Formation of Effective Informal Support Networks
}

\author{
Deone Zell \\ California State University, Northridge \\ College of Business Administration and Economics \\ 18111 Nordhoff Street \\ Northridge, CA 91330 \\ Tel: $818-677-4500$ \\ E-mail: deone.zell@csun.edu \\ Cathleen McGrath \\ Loyola Marymount University \\ College of Business Administration \\ 1 LMU Drive \\ Los Angeles CA 90045 \\ Tel: (310) 338-4585 \\ E-mail: cmcgrath@lmu.edu \\ Charles M. Vance \\ Loyola Marymount University \\ College of Business Administration \\ 1 LMU Drive \\ Los Angeles CA 90045 \\ Tel: (310) 338-4508 \\ E-mail: cvance@1mu.edu
}

\begin{abstract}
This study on informal support networks bridges the traditionally disparate disciplines of personality theory and social network theory, and examines the impact of extroversion on the structure of support networks, as well as the relative contribution of network structure versus extroversion to a critical element of network effectiveness: trust. Two questionnaires measuring extroversion and social support network characteristics were administered to 113 university business students. Although no impact of extroversion was found on certain dimensions of network structure (e.g., size, diversity, behavioral aspects of strength of ties), introverts and extroverts differed in terms of affective aspects of strength of ties and embeddedness. Furthermore, although we failed to find a significant interaction effect of extroversion and embeddedness on trust, both extroversion and strength of ties predicted trust. In addition, extroverts' networks were characterized by higher levels of intimacy and trust, which may
\end{abstract}


translate into benefits not available to introverts. Knowledge of this difference can help introverts improve their networking effectiveness by enabling them to compensate for personality traits.

\section{Introduction}

Informal support networks, a type of social network, refer to the unique collection of individuals who people seek out and rely on for credible information, sound advice, or emotional support (Dobrow, Chandler, Murphy \& Kram, 2012; McGrath, Vance \& Gray, 2003). Individuals actively create and modify their informal support networks based upon their experience with individuals with whom they come in contact (McGrath \& Zell, 2009). Contacts that individuals may select for their informal support network may come from a variety of sources - e.g., friends, family, neighborhood acquaintances, former schoolmates, and members of more formal networks, such as workplace colleagues and supervisors (Bruning, Sonpar \& Wang, 2012; Hawkins \& Maurer, 2012; Wellman \& Wortley, 1990). The benefits of effective informal networks have been clearly documented in a variety of realms such as organizational effectiveness (Berardo, 2009; Cross et al., 2002), organizational innovation (Fu, Diez \& Schiller, 2013; Salavisa, Sousa \& Fontes, 2012; Obstfeld, 2005) and career advancement (Baber \& Waymon, 2007; Burt, 1992). According to social network theory, the structure of social networks plays the primary role in their effectiveness. For example, social networks that are large, diverse, rich in weak ties to casual acquaintances, and "structural holes" (gaps between diverse groups) lead to a range of positive outcomes including access to novel sources of information (Burt, 1992; Granovetter, 1973), fruitful inventions (Burt, 2004), and the discovery of new jobs (Granovetter, 1995). Conversely, networks that are small, dense, and rich in strong ties to close friends and family who are highly embedded have their own benefits, as such relationships often represent our mentors, advocates and allies who not only provide political and emotional support but whose investment in us can help mobilize resources to achieve complex or difficult breakthroughs - either individually or organizationally (Baker, 1993; Obstfeld, 2005). The effectiveness of informal support networks, specifically, depends on the composition and structure of the network (Leung, Xin, Priem, \& Shaffer, 2013).

Regardless of whether networks are large or small, dense or sparse, or whether relationships are strong or weak, at the heart of a network's effectiveness is trust. As the basis for social control in networks, trust between individuals guarantees that they will not be taken advantage of in uncertain or risky situations. Without trust there would be no guard-other than institutional backing - against lack of reciprocation, dishonesty, or betrayal. Thus, while networks provide critical access to resources, trust is the insurance policy that prevents exploitation, enables cooperation, and facilitates social exchange (Kuo, 2013; Chang \& Cheng, 2013; Covey, 2006; Barber, 1983; Hardin, 1996; Luhmann, 1979). At the societal level, networks that lack trust are unable to yield the "social capital" (the collective value of social networks that is rooted in the inclination to do things for each other) needed to build and maintain a democracy (Abdulkadiroglu \& Bagwell, 2013; Putnam, 1995). At least minimum levels of trust are required for individuals to activate and use the contacts that they have in their support networks. Without trust, information cannot be deemed credible, advice cannot be heeded, and emotions cannot be revealed — at least not without considerable risk (Zolin et al., 2004; Rousseau, Sitkin, Burt \& Camerer, 1998). 
Social network theorists and personality theorists differ in the factors they believe lead to the establishment of robust, trusting social networks. According to social network theory, trust is primarily a function of network structure (Turkina \& Thai, 2013; Gulati, 1995; Buskens, 1998). Trust develops with increased interaction between individuals and dense network connections because trust takes time to evolve and interconnections between people serve to corroborate perceptions and establish social norms (Granovetter, 1973). Personality theory, in contrast, would suggest that the development of extensive, trusting relationships is a function of individuals' personality traits such as agreeableness and especially extroversion (Swickert, Hittner \& Foster, 2010; Stewart \& Barrick, 2000; Bruch et al, 1989; Cheek \& Buss, 1981). Individuals who are warm, modest, good-natured, energetic, sociable, outgoing, and gregarious - versus those seemingly cold, stern, quiet, withdrawn, critical, and shy, are presumably more apt to build trusting and expansive networks (Asendorph \& Wilpers, 1998; Paunonen 2003; Ozer \& Benet-Martinez, 2006).

Yet the relative contribution of social network structure versus personality to network effectiveness (i.e., featuring trust) has been little researched, primarily because personality theory and social network theory represent disparate disciplines rooted in different assumptions and theoretical frameworks. Social network theorists typically subscribe to the "structuralist perspective," in which their focus is on the structure of relationships between actors in the network rather than on attributes of the actors themselves (Pfeffer, 1991; Blau, 1993). Individual characteristics are often omitted from network analyses either because (1) they are assumed to arise (at least in part) from the relational systems in which they are embedded, and are therefore dismissed as the "spuriously significant attributes of people temporarily occupying particular positions in social structure" (Burt, 1986:106); or because (2) personality characteristics are considered too difficult to measure, especially in comparison to the consequential and tractable nature of network structure (McPherson et al., 1992; Burt et al., 1998). Psychological research also has tended to neglect the link. Despite considerable psychological research suggesting that personality plays a role in the development of family, peer, and romantic relationships (see Ozer \& Benet-Martinez, 2006), as well as in popularity, status (Paunonen, 2003), social acceptance (Anderson et al., 2001), and social influence (e.g., McGuire, 1968; Riley and Eckenrode, 1986), relatively little work has been done in psychology that examines the impact of personality on the structure and characteristics of social networks in which people work and live (Mehra et al., 2001).

Recently, in part due to the increasing exchange between sociologists and psychologists in applied studies of organizational behavior, there has been increased recognition of the importance of individual differences above and beyond differences attributable to network structure (Burt et al., 1998). The intersection of personality and social networks is now considered an area in need of additional research (Emirbayer \& Goodwin, 1994; Mehra, Kilduff \& Brass, 2001), and represents an emerging and potentially rich area for organizational behavior scholars (Cross, 2002). With this increasing interest in studying the junction between personality and social networks, the purpose of this study is to explore how individual personality traits may interact with social network structure to form effective informal support networks that are rich in trusted contacts. In particular, we investigate the impact of the personality trait of extroversion on key characteristics of network structure. In addition, we aim to determine the relative contribution of extroversion and network structure to a critical determinant of network value and effectiveness: trust (Covey, 2006; Hardin, 1996). 


\section{Characteristics of Informal Support Network Structure}

Informal support networks describe a set of contacts that are directly connected to an individual. Each contact in an individual's support network also likely shares membership in at least one larger network that may be a formal network such as the organization where an individual is employed. In fact, many of these informal support contacts emerge from formal network relationships. In this study, we expected that advice contacts emerge primarily from individuals' family, friendship, school and work networks. While we asked individuals specifically about their support network, we acknowledge that each member of the support network also shares a role in a larger network, whose structure may also impact the way individuals and their contacts interact. Four structural characteristics of informal support networks that are considered to play a key role in network effectiveness are size, strength of ties, embeddedness, and diversity. We now will examine each of these in more detail.

Network size. The size of an individual's informal support network can influence the amount and variety of resources available for all forms of support. Network size has been identified as a key determinant of health and wellbeing (Chan \& Lee, 2006). Related to entrepreneurship effectiveness, as an individual's social network boundary is extended, more new venture ideas and opportunities may be recognized and exploited (Singh, Hybels \& Hills, 2000). At the same time, having more contacts requires more energy so at some point, the returns to size may be diminishing.

Strength of ties. Relationships with others can be considered strong or weak. Typically, weak ties represent casual acquaintances - people we have known for limited amounts of time and with whom we interact with occasionally, while strong ties represent close friends and allies whom we have known for long periods of time and with whom we frequently interact. The strength of one's ties is traditionally considered to be a function of four factors: (1) the amount of time people spend together, (2) the emotional intensity, or depth of feeling felt between two people; (3) intimacy, or the degree to which people confide in each other (e.g., share information that may be personal, sensitive, or confidential in nature), and (4) reciprocity, or the degree to which attitudes, feelings or services are mutually reciprocated (Granovetter, 1973).

Embeddedness. Embeddedness describes the degree to which any given contact in an individual's support network is connected to other contacts in the network. As contacts in the support network become more embedded, the overall support network becomes more dense. Embeddedness tends to be positively correlated with strength of ties because the more strongly an individual is connected with a contact in his/her network, the more likely that individual is to introduce the contact to other contacts in the network (Granovetter, 1985, 1992).

Diversity. Individuals' networks can be homogenous, made up of similar others, or diverse and heterogeneous. However, individuals' support networks tend to be homogenous because as noted by homophily theory, individuals tend to connect with others who they perceive to be similar to themselves (McPherson et al, 2001). Diversity tends to be negatively correlated with strength of ties and embeddedness because in general, the more diversity that exists within a group, the lower the likelihood of interaction between members of the network (Burt, 2004; 
Granovetter, 1973). While diverse support networks may take more effort to maintain, the diversity will provide individuals with access to multiple perspectives and different expertise. 


\section{Impact of Extroversion on Network Structure}

Extroversion is associated with an energetic approach to the social and material worlds and implies traits such as friendliness, gregariousness, assertiveness, excitement-seeking, and cheerfulness (Pervin \& John, 1999; Costa \& McCrae, 1992; John, 1990). Extroverts typically are characterized as being talkative, outgoing, energetic, enthusiastic and lively, and as preferring to be around people much of the time (Pervin \& John, 1999; Johnson, 2005). They are "understandable and accessible, often sociable, more at home in the world of people and things than in the world of ideas" (Myers \& Myers, 1980: 56). In contrast, introverts tend to draw energy from the inner world and are typically described as quiet, reserved, withdrawn and retiring (Pervin \& John, 1999). They are "subtle and impenetrable, often taciturn and shy, more at home in the world of ideas than in the world of people" (Myers \& Myers, 1980: 56). They tend to enjoy solitude and solitary activities, and to restrict their socializing to a few close friends (Johnson, 2005).

Extroversion, the personality trait most closely linked to effective social relationships, has been shown to have an impact on a wide variety of outcomes such as peer acceptance and friendship (Jensen-Campbell et al., 2002), relationships with parents (Belsky et al., 2003), popularity and status (Paunonen, 2003), social acceptance (Anderson et all, 2001; Ozer et al., 2006), and international social adjustment (Huang, Chi, \& Lawler, 2005). Yet research on the relationship between extroversion and social network structure is scant and inconclusive. Some studies have found that extroversion does play a role in shaping individuals' support networks. Asendorph \& Wilpers (1998) found that extroversion predicted the size of peer networks and how much time individuals spent interacting with their peers. Swickert, et al. (2002) also found a positive correlation between extroversion and support network size. Burt et al. (1998) found that the networks of extroverts tend to have more structural holes than those of introverts, suggesting that extroverts' networks are more diverse and richer in weak ties. Similarly, Cohen et al. (2000) found that extroverts tended to have more diverse networks (and presumably, more weak ties and structural holes) than introverts.

Other researchers, however, have found little or no relationship between extroversion and network structure. Klein et al. (2004) found that extroversion failed to predict friendship or advice centrality. While he doesn't cite any published studies, Cross mapped personality scales such as the Myers-Briggs on social network analyses and found that the "link between someone's personality and his or her position in a network is not as strong as one might think. Even highly introverted people," he says, "can and often do, have robust personal networks" (Cross et al., 2002:73). So sure is he of the lack of a connection between personality traits and network position that he labels this notion a "myth," and maintains instead that a better predictor of network position are individuals" "intentional behaviors" (p. 73) — in other words, the degree to which they realize and act on the value of relationships (Cross et al., 2002).

Given these conflicting findings, what impact does extroversion actually have on network characteristics such as size, diversity, strength of ties, and embeddedness? Based on the assumption that extroverts are characterized as being gregarious, assertive and highly social, we would expect that extroverts have larger networks than introverts.

Hypothesis 1: Extroverts will have support networks that are larger than those of introverts. 
Due to their gregariousness, we anticipate that extroverts reach out to many different types or categories of people from different walks of life, resulting in networks that are more diverse than those of introverts.

Hypothesis 2: The support networks of extroverts will be more diverse than those of introverts.

Due to the ease with which they reach out to people (e.g., relative strangers), we anticipate that extroverts have higher proportions of weak ties (e.g., casual acquaintances) in their networks than those of introverts.

Hypothesis 3: Extroverts' support networks will have higher proportions of weaker ties than those of introverts.

Since weak ties are associated with lower levels of embeddedness, we hypothesize that the networks of extroverts display this same characteristics.

Hypothesis 4: Contacts in extroverts' support networks will be less embedded than those in introverts' support networks.

\section{Determinants of Trust}

As noted earlier, trust is the basis for social exchange between individuals that determines the degree to which individuals utilize their networks. An individual's propensity to trust is thought to depend on their perceptions of three characteristics of the trustee: (1) Benevolence, or the extent to which the trustor believes the trustee has the trustor's best interest at heart, in the absence of extrinsic rewards; (2) Ability, or the trustee's perceived skillfulness, competence, or expertise about a certain topic or matter; (3) Integrity, or the trustor's belief that the trustee adheres to a set of moral and ethical principles that the trustor finds acceptable (Rotter, 1967; Mayer et al., 1995). Trust between two people can be a function of the structural dimensions of their network relationship (e.g., strength of ties, embeddedness, and diversity) or of the trustor's personality. Here we develop hypotheses about the effect of each on the development of trust between individuals and their support network contacts.

Personality. Personality theory suggests that individuals' inclination to trust others, or their "propensity to trust," is a function of relatively stable personality traits such as agreeableness and extroversion (Asendorph, 1998). Kroeger and Thuesen (1988), for example, suggest that extroversion correlates with greater extension of trust because even if extroverts know more people, they count many of them among their close friends. We therefore hypothesize that extroverts have greater propensity to trust, as measured by the above three trust characteristic dimensions of a trustee, and therefore extend greater amounts of trust both to their contacts in general and to their weak ties.

Hypothesis 5: Extroverts extend greater amounts of trust to their support network contacts, both in general as well as to their weak ties.

Strength of ties. In concordance with the literature, we predict that strength of ties is positively correlated with trust because as people get to know each other better, levels of trust increase (Mayer et al., 1995; Coleman, 1994).

Hypothesis 6: Strong ties to support contacts are positively related to trust. 
Embeddedness. Consistent with the social network literature, we predict that embeddedness is conducive to trust because interconnections between people serve to increase credibility, and lead to alignment of interests and the establishment of social norms (Granovetter, 1985, 1992; Uzzi, 1997).

Hypothesis 7: Individuals extend a greater amount of trust to their embedded contacts than to their non-embedded contacts.

Diversity. Diversity tends to be negatively correlated with strength of ties, density, and embeddedness because in general, the more diversity that exists within a network, the lower the likelihood of interaction between members of the network (Burt, 2004; Granovetter, 1973; McPherson, Smith-Lovin \& Cook, 2001). According to social network theory, it follows that diverse networks would also be lower in trust.

Hypothesis 8: Diversity is negatively related to trust.

Interaction between extroversion and embeddedness. Furthermore, we hypothesize that embeddedness is more important to introverts because of the added credibility that it provides, e.g., the more people in an introvert's network that any given contact knows, the more "trustworthy" that contact will seem to the introvert. Conversely, due to their propensity to trust, embeddedness will have little bearing on the degree of trust extroverts place in their contacts.

Hypothesis 9: Introverts require higher levels of embeddedness to build up the same levels of trust with contacts as extroverts.

\section{Methods}

Data for the study came from a sample of 113 undergraduate students enrolled in an introductory class on management and organizational behavior at a public university in Southwest United States. Students who participated in the study ranged in age from 21 to 45 years, with an average of 25 years, and about half were female. Students ranged in ethnicity including Caucasian, Hispanic, African American, Middle Eastern, Indian, East Asian. Because the class was an upper-division business course, students were either juniors or seniors and came from a variety of majors, including Marketing, Management, Finance, Business Law, Economics, and Operations. The sample was comprised of 40 introverts and 73 extroverts. These 113 students yielded 1,065 contacts about which a variety of characteristics (e.g., strength of ties, embeddedness) were obtained and analyzed using test of correlation, ANOVA, and General Linear Modeling.

Students were considered suitable proxies for organization members for several reasons. Since most research suggests that personality traits are relatively fixed by adolescence/early adulthood (McCrae et al., 2000) with moderate changes occurring over the life course (Roberts et al., 2006), we reasoned that college students would provide especially pure measures of personality compared to older, more seasoned organization members. In addition, we anticipated that since most undergraduates may not yet fully grasp the importance of networking, they would be relatively untainted by intentional behaviors, making it even easier to isolate the main effect of personality. Finally, we reasoned that the activities of students and organization members was equivalent in terms of the "core work" each performs: while students must network with others in order to complete their coursework and obtain a degree, organization members must network 
with others to accomplish the daily activities and tasks associated with meeting organizational goals.

\section{Table 1}

\section{Social Network Measures on Instrument \#1}

\section{Size of network}

- $\quad$ Number of people listed (up to 20)

\section{Composition of network}

- Percentage of friends, family members, work-contacts, classmates, faculty, staff, other

\section{Strength of ties:}

Behavioral

- Time: How often do you talk to this person?

- 1-less than once/month

- 2-at least once/month

- 3-at least once/week

○ 4-at least once/day

- Time: How long have you known this person?

- 1-less than once a year

- 2-1-3 years

○ 3-more than 3 years

- Intimacy: How often share personal information with this person, relative to how often you speak?

o 1-never

○ 2-rarely

- 3-sometimes

○ 4-very frequently

- $\quad$ Advice Reciprocity: Do you provide help to this person as well?

$$
\begin{array}{ll}
\circ & 1 \text {-no } \\
\circ & 2 \text {-yes }
\end{array}
$$

Affective

- Intimacy: Would you be comfortable asking to borrow $\$ 10$ from this person

$$
\begin{array}{ll}
\circ & 1 \text {-no } \\
\circ & 2 \text {-yes }
\end{array}
$$

- Intensity: How sad would you be if the relationship ended?

- 1-not at all

- 2-somewhat

o 3-very

\section{Density}

- $\quad$ Number of other people on list each person knows

\section{Trust}

- $\quad$ Expertise: How knowledgeable do you consider this person to be about the topics you discuss?
- 1-not at all
o 2-somewhat
- 3-very

- Benevolence: How committed to your best interests would you say this person is?

○ 1-not at all

o 2-somewhat

o 3-very

- Integrity: How would you rate this person's integrity, or ethical behavior?
- 1-low
- 2-medium
- 3-high 
Two separate questionnaires were administered. The first instrument was designed to gather information about respondents' informal support networks such as network size, strength of ties, composition, and embeddedness. A summary of the measures contained in the first instrument is shown in Table I. Respondents were asked to list up to 20 key individuals they go to for information, advice, or support regarding any school-related topics (e.g., which classes to take, worries about a bad grade, which major to pick, where to get a parking permit), and then to answer a series of questions about each person in their network.

Extroversion versus introversion was assessed in a separate online survey version of the Jung's Typology Test. Extroversion was determined by 18 items (see Table II). As commonly used in previous studies (Aharony, 2013; Bradley-geist \& Landis, 2012; Zarafshani \& Somayeh, 2011), we employed a dichotomous variable methodology in measuring the constructs of extroversion and introversion.

Table 2

Extroversion Measures on Instrument \#2

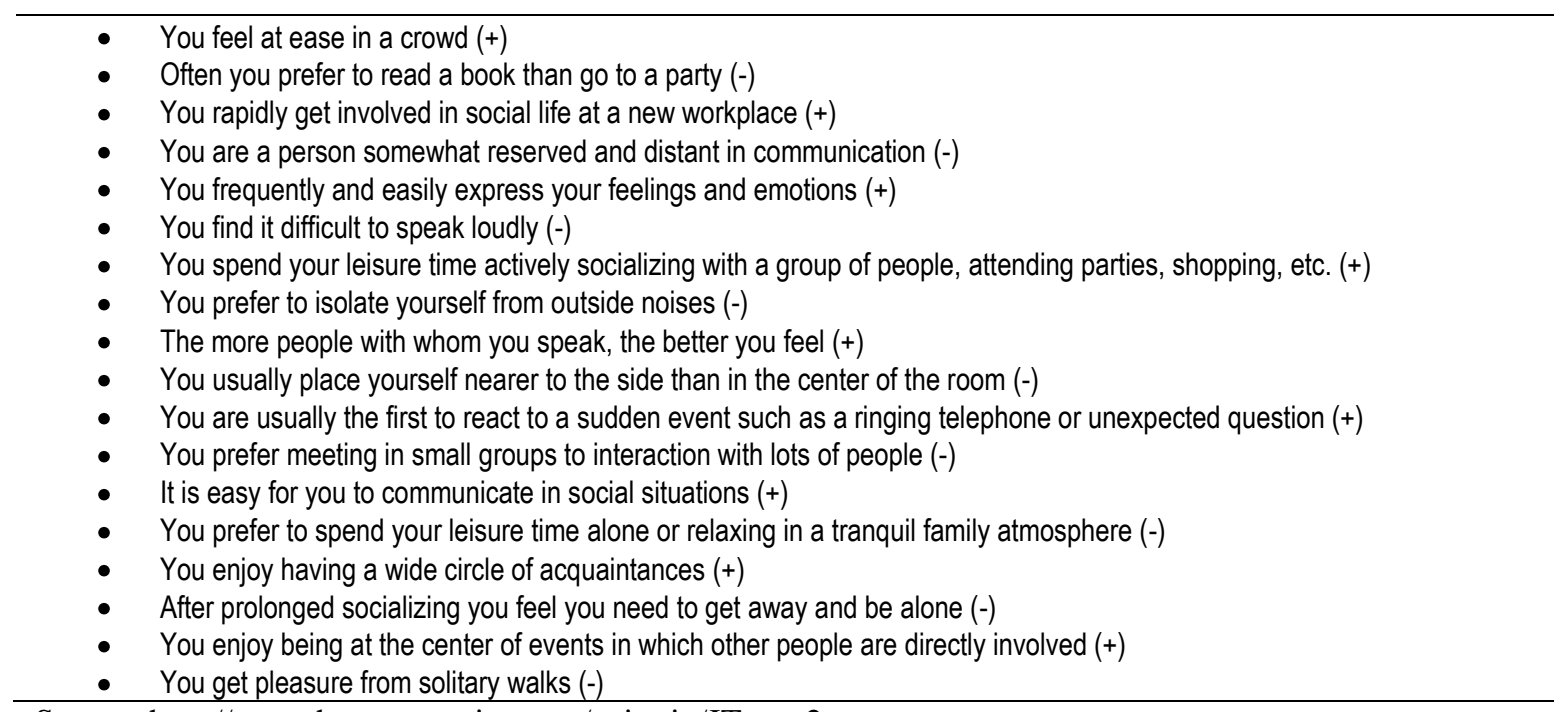

Source: http://www.humanmetrics.com/cgi-win/JTypes2.asp

Note: Items with a "+" measured extroversion, while items with a "_" measured introversion.

The two instruments were administered to the undergraduates over the course of four weeks. Our research questions address personality characteristics, which are measured at the individual level, as well as structural characteristics of respondents' networks, which are measured at the relationship level. Therefore, analyses were conducted at both the individual (e.g., 113 respondents) and relational (e.g., 1,065 contacts) levels. Table III shows the descriptive statistics and correlation coefficients for relational variables. 
Table 3

Pearson Correlation Coefficients, $N=932$

\begin{tabular}{|c|c|c|c|c|c|c|c|c|c|c|c|c|c|}
\hline & & Mean & 1 & 2 & 3 & 4 & 5 & 6 & 7 & 8 & 9 & 10 & 11 \\
\hline 1. & Trust & 7.71 & & & & & & & & & & & \\
\hline 2. & Competence & 2.47 & .719 & & & & & & & & & & \\
\hline 3. & Benevolence & 2.57 & .744 & .248 & & & & & & & & & \\
\hline 4. & Integrity & 2.68 & .751 & .327 & .379 & & & & & & & & \\
\hline 5. & Strength & 14.46 & .406 & $.113^{* *}$ & .569 & .204 & & & & & & & \\
\hline 6. & Frequency & 3.04 & .179 & .015 & .311 & .061 & .648 & & & & & & \\
\hline 7. & Duration & 2.33 & .237 & .045 & .336 & .139 & .593 & .067 & & & & & \\
\hline 8. & Personal & 3.01 & .358 & .150 & .448 & .184 & .794 & .394 & .316 & & & & \\
\hline 9. & Help & 1.85 & $.093^{*}$ & -.040 & .196 & .048 & .498 & .377 & $.088^{*}$ & .314 & & & \\
\hline & Borrow & 1.69 & .302 & .083 & .462 & $.110^{\star \star}$ & .707 & .302 & .396 & .500 & .328 & & \\
\hline & Sad & 2.55 & .432 & .161 & .531 & .258 & .766 & .318 & .460 & .530 & .281 & .537 & \\
\hline & Embedded & .40 & .164 & .036 & .254 & .066 & .438 & .245 & .375 & .306 & .156 & .317 & .337 \\
\hline & Extrovert & .62 & $.121^{1 *}$ & $.010^{*}$ & $.106^{\star \star}$ & .061 & .042 & .011 & -.020 & .052 & -.018 & $.088^{*}$ & .060 \\
\hline
\end{tabular}

Notes:

1) Bold $\mathrm{p}<.0001, * * \mathrm{p}<.001, * \mathrm{p}<.01$

2) Table includes all observations with no missing variables for all variables reported)

3) $\operatorname{Pr}>|r|$ under Rho=0

\section{Strength of Ties}

The four components of strength of relationships identified by Granovetter (1973) were represented by a total of six questions: two for time spent together, two for intimacy, one for intensity, and one for advice reciprocity. Cronbach's alpha was used to determine the reliability of these six questions, and was found to be at the acceptable level of .755. All six dimensions were found to be positively correlated with each other at either the $p=.05$ or $p=.01$ level.

Construction of strength of ties scale. The six components of strength of ties were used to construct a scale by adding up each of the six components. The scale could therefore range in value from 6 to 18 . The average was 14.5 with a standard deviation of 2.8 .

In this paper we extend the traditional dimensions of strength and suggest that the construct can also consist of behavioral versus affective dimensions. The behavioral dimension pertains to observable, measurable components, and included four of the six components of strength of ties (frequency of interaction, length of time known, frequency of sharing personal information, and advice reciprocity), while the affective dimension is based on emotions, which greatly influence the formation and use of informal social networks, and refers to how someone "feels" about the relationship. The affective dimension was based on two measures: the degree of comfort at the prospect of asking to borrow a small sum of money and the depth of sadness anticipated should the relationship end.

\section{Embeddedness and Density}

The extent to which each member of the support network is connected to others in the support network is measured as embeddedness. As individual contacts become more embedded in the support network, the overall support network density increases. For example, a respondent 
may report a contact that also knows all of his or her other contacts. That contact would have an embeddedness score of 1 . A contact that knew no one else in a respondent's network would have embeddedness score of 0 . The formula for embeddedness is the number of other contacts in a given network that each contact is connected to, divided by the total number of contacts in the network, as per the following:

$$
\text { Embeddedness }=\frac{j}{n-1}
$$

where $j$ is the number of connections for each contact and $n$ is the total number of contacts

While embeddedness describes a characteristic of a respondent's contacts, network density describes the respondent's overall support network. Density is measured as the total number of connections among the focal respondents' support contacts, divided by the total possible number of connections among the focal respondents' support contacts, or

$$
\text { density }=\frac{\prod_{j=1}^{n} \text { number of contacts } j \text { knows }}{n(n-1)}
$$

where $j$ is the number of connections for each contact and $n$ is the total number of contacts.

\section{Diversity}

Diversity is defined as the number of different categories of contacts that an individual turns to for advice. There were seven possible categories of contacts (friends, family, work, classmate, faculty, staff, other). Thus, diversity could range in value from 1 - when all contacts come from the same category to 7 - where all categories are represented in the support network. The average number of categories was 3.4 , with a standard deviation of 1.2 .

\section{Results}

Table III shows the correlation matrix of the variables of the present study at the relationship level. In a more focused analysis of variables, Tables IVa and IVb indicate that strong correlations were found between structural characteristics of support networks - strength of ties, embeddedness of contacts, density of the support network, and diversity of the support network - all directions that would have been predicted by social network theory.

Table 4a

Relationship between Strength, Trust, and Embeddedness

Calculated at the Relationship Level $(n=1027)$

\begin{tabular}{lccc}
\hline & \multicolumn{3}{c}{ Pearson Correlations } \\
\cline { 2 - 4 } & Strength & Trust & Embeddedness \\
\hline Strength & 1 & $.431^{* *}$ & $.436^{* *}$ \\
Trust & & 1 & $.169^{* *}$ \\
Embeddedness & & & 1 \\
\hline
\end{tabular}

Note: Strength and Trust measured are based on scales.

** Correlation is significant at the 0.01 level (2-tailed).

* Correlation is significant at the 0.05 level (2-tailed). 
Table $4 b$

Relationship between Strength, Trust, Density, and Diversity,

Calculated at Individual Level $(n=115)$

\begin{tabular}{lcccl}
\hline & \multicolumn{3}{c}{ Pearson Correlations } \\
\cline { 2 - 5 } & Average Strength & Average Trust & Density & Diversity \\
\hline Average Strength & 1 & $.534^{\star *}$ & $.510^{* *}$ & $-.302^{\star *}$ \\
Average Trust & & 1 & $.221^{*}$ & -.052 \\
Density & & & 1 & -.357 \\
Diversity & & & & 1 \\
\hline
\end{tabular}

Note: Strength and Trust are averages calculated at the individual level

** Correlation is significant at the 0.01 level (2-tailed).

* Correlation is significant at the 0.05 level (2-tailed).

Table 5

Support Network Size, Composition and Diversity Introverts versus Extroverts

\begin{tabular}{|c|c|c|c|}
\hline & $\begin{array}{c}\text { Introverts } \\
(n=40) \\
\text { Mean }\end{array}$ & $\begin{array}{c}\text { Extroverts } \\
(n=73) \\
\text { Mean }\end{array}$ & $\begin{array}{c}\text { ANOVA } \\
\text { (signific. } \\
\text { level) }\end{array}$ \\
\hline \multicolumn{4}{|l|}{ SIZE } \\
\hline Number of connections & 9.5 & 8.6 & 0.24 \\
\hline \multicolumn{4}{|l|}{ COMPOSITION } \\
\hline Average number of friends & 4.6 & 4.5 & 0.91 \\
\hline Average number of family members & 2.4 & 2.1 & 0.34 \\
\hline Average number of work contacts & 0.8 & 0.7 & 0.58 \\
\hline Average number of classmates & 2.0 & 1.4 & 0.09 \\
\hline Average number of faculty & 0.4 & 0.5 & 0.76 \\
\hline Average number of staff & 0.3 & 0.3 & 0.84 \\
\hline Average number of other & 0.3 & 0.3 & 0.78 \\
\hline Percent friends & 46.0 & 53.0 & .144 \\
\hline Percent family & 28.7 & 24.7 & .290 \\
\hline Percent work contacts & 8.2 & 9.4 & .649 \\
\hline Percent classmates & 21.0 & 15.2 & .162 \\
\hline Percent faculty & 4.3 & 5.0 & .746 \\
\hline Percent staff & 3.1 & 3.3 & .938 \\
\hline Percent other & 3.1 & 3.4 & .884 \\
\hline \multicolumn{4}{|l|}{ DIVERSITY } \\
\hline Average number of categories & 3.6 & 3.4 & .354 \\
\hline
\end{tabular}

Hypothesis 1 was not supported comparing the size of networks between extroverts and introverts. That is, no difference between introverts and extroverts in terms of the size of their 
informal support networks was found (see Table V). As also indicated in Table V, we found no differences between introverts and extroverts in the diversity of their networks, thus failing to support Hypothesis 2. Extroverts tended to have higher proportions of friends while introverts tended to have higher proportions of family members and classmates; however, these differences were not statistically significant.

Hypothesis 3, predicting a positive link between extroversion and weak ties, was partially supported. No significant difference was found in overall strength of ties between introverts and extroverts. However, when strength of ties was broken down into behavioral and affective components, differences emerged. As discussed in the methods section, behavioral aspects pertain to observable, measurable behaviors, while affective components are based on emotions and refer to how someone "feels" about the relationship. While there were no differences between introverts and extroverts with regard to the behavioral components of strength of ties, extroverts felt significantly more strongly regarding the affective components (see Table VI). As also depicted in Table VI, contrary to our Hypothesis 4, we found a positive relationship between extroversion and contact embeddedness, suggesting that contacts of extroverts are significantly more - rather than less - embedded than those of introverts.

Table 6

Support Network Characteristics:

Introverts versus Extroverts

\begin{tabular}{|c|c|c|c|c|}
\hline \multirow[b]{2}{*}{ Metric } & \multirow[b]{2}{*}{ Range } & \multicolumn{2}{|c|}{ Mean } & \multirow[b]{2}{*}{ ANOVA } \\
\hline & & $\begin{array}{c}\text { Introverts } \\
(n=380)\end{array}$ & $\begin{array}{c}\text { Extroverts } \\
(n=640)\end{array}$ & \\
\hline \multicolumn{5}{|l|}{ RELATIONSHIP LEVEL } \\
\hline Strength-scale & $6-18$ & 14.31 & 14.59 & .138 \\
\hline \multicolumn{5}{|l|}{ Behavioral } \\
\hline$\overline{\text { How often talk }}$ & $1-4$ & 3.01 & 3.05 & .528 \\
\hline How long known & $1-4$ & 2.35 & 2.32 & .495 \\
\hline How often share personal info & $1-4$ & 2.96 & 3.05 & .141 \\
\hline Provide help to as well & $1-2$ & 1.86 & 1.84 & .398 \\
\hline \multicolumn{5}{|l|}{$\underline{\text { Affective }}$} \\
\hline Comfort at asking to borrow $\$$ & $1-2$ & 1.65 & 1.71 & $.025^{\star *}$ \\
\hline Sadness should relationship end & $1-3$ & 2.50 & 2.59 & $.041^{* *}$ \\
\hline Trust-scale & $3-9$ & 7.54 & 7.87 & $.000^{* *}$ \\
\hline Competence & $1-3$ & 2.41 & 2.54 & $.000^{* *}$ \\
\hline Benevolence & $1-3$ & 2.50 & 2.62 & $.001^{* *}$ \\
\hline Integrity & $1-3$ & 2.64 & 2.71 & $.051^{*}$ \\
\hline Embeddedness & $0-1$ & .410 & .461 & $.011^{* *}$ \\
\hline \multicolumn{5}{|l|}{ INDIVIDUAL LEVEL1 } \\
\hline Density & $0-1$ & .49 & .47 & .609 \\
\hline
\end{tabular}


Hypothesis 5 was supported regarding the influence of extroversion on trust. Extroverts were found to feel significantly more trusting toward their contacts in general (see Table VII). Also depicted in Table VII, extroverts placed higher trust in contacts with whom they reported to have weak ties as measured by the behavioral components.

Hypothesis 6 was supported in our results with both a positive correlation between strength of ties and trust (see Tables IVa and IVb) and a main effect for impact of strength of ties on trust, even after controlling for extroversion using the General Linear Model procedure (see Table VIII) and structural equation modeling (see Figure 1).

Although initially we found that embeddedness was positively correlated with trust (see Table IVa), when we controlled for personality and strength of ties using the General Linear Model and structural equation modeling procedures (see Table III and Figure 1), the correlation between embeddedness and trust disappeared, thus failing to support Hypothesis 7. This suggests that embeddedness has no direct influence on trust - but rather, that embeddedness is simply a function of strength of ties (e.g., the more we interact with the contacts in our network, the more they become acquainted with each other).

Table 7

High Trust Placed in Weak Ties:

Introverts versus Extroverts

\begin{tabular}{|c|c|c|c|}
\hline \multirow[b]{2}{*}{ Weak Ties Only } & \multicolumn{3}{|c|}{$\begin{array}{l}\text { Percent in Which High } \\
\text { Trust is Placed }\end{array}$} \\
\hline & $\begin{array}{c}1 \\
(n=380)\end{array}$ & $\begin{array}{c}E \\
(n=640)\end{array}$ & Chi-square \\
\hline \multicolumn{4}{|l|}{ Behavioral } \\
\hline Talk to once per week or less (versus once a day) & 51.6 & 63.8 & $.001^{* *}$ \\
\hline $\begin{array}{l}\text { Known for three years or less (versus more than three } \\
\text { years) }\end{array}$ & 42.8 & 61.7 & $.000^{\star *}$ \\
\hline $\begin{array}{l}\text { Share personal information with sometimes, rarely or never } \\
\text { (versus frequently) } \\
\text { Affective }\end{array}$ & 48.8 & 61.2 & $.001^{* *}$ \\
\hline Not comfortable asking to borrow $\$ 10$ from this person & 43.3 & 49.2 & 177 \\
\hline Not at all or somewhat sad if the relationship ended & 37.2 & 43.5 & .132 \\
\hline
\end{tabular}

Notes: (1) A week tie was defined by using what we considered to be weak values for each component of strength (e.g., talking to a contact once per week or less versus once a day, having known them for three years or less versus more than three years, etc.)

Hypothesis 8 was not supported. While we found a negative correlation between diversity and trust, the correlation was not significant, suggesting that diversity in networks is not associated with elevated levels of trust. In addition, as shown in the results from the General Linear Model in Table VIII, we found no interaction effect between extroversion and embeddedness. This finding suggests that, contrary to our Hypothesis 9, having contacts that are highly embedded is of no more benefit to introverts than to extroverts in terms of the development of trust. 
Table 8

Predicting Trust from Personality, Strength and Embeddedness

\begin{tabular}{|c|c|c|c|c|c|}
\hline \multicolumn{6}{|c|}{$\begin{array}{l}\text { Tests of Between-Subjects Effects } \\
\text { Dependent Variable: Trust }\end{array}$} \\
\hline Source & $\begin{array}{l}\text { Type III Sum of } \\
\text { Squares }\end{array}$ & $\mathrm{df}$ & $\begin{array}{l}\text { Mean } \\
\text { Square }\end{array}$ & $\mathrm{F}$ & Sig. \\
\hline Corrected Model & $263.006^{\mathrm{a}}$ & 4 & 65.751 & 52.062 & 0.000 \\
\hline Intercept & 334.171 & 1 & 334.171 & 264.596 & 0.000 \\
\hline Strength & 201.998 & 1 & 201.998 & 159.942 & 0.000 \\
\hline Embeddedness & 0.064 & 1 & 0.064 & 0.051 & 0.821 \\
\hline Extroversion & 5.619 & 1 & 5.619 & 4.449 & 0.035 \\
\hline Embeddedness X Extroversion & 0.000 & 1 & 0.000 & 0.000 & 0.993 \\
\hline Error & 1188.432 & 941 & 1.263 & & \\
\hline Total & 57876.000 & 946 & & & \\
\hline Corrected Total & 1451.438 & 945 & & & \\
\hline
\end{tabular}

${ }^{\mathrm{a}} \mathrm{R}$ Squared $=.181$ (Adjusted R Squared $=.178$

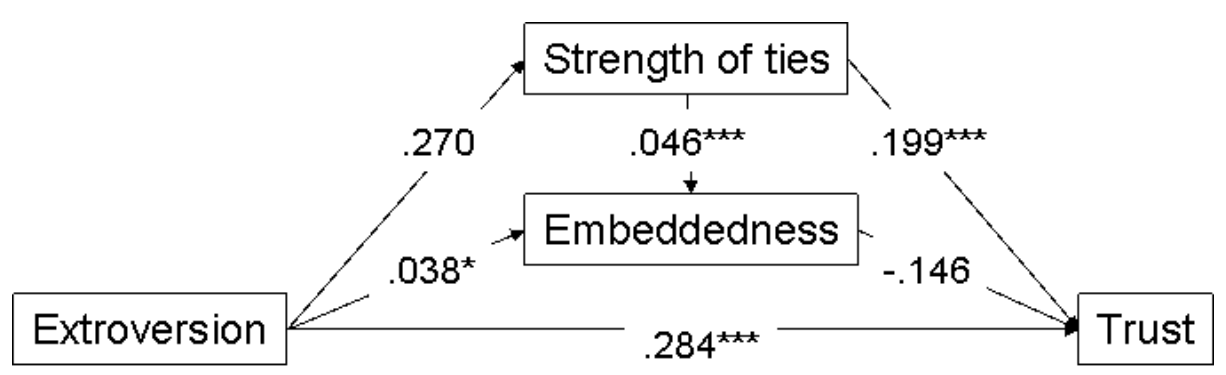

Notes: (1) Strength and trust measures are scales based on sums of components

(2) Numbers are unstandardized regression coefficients

(3) Strength is a composite made up of all six components.

(4) * indicates significance at the .05 level

** indicates significant at the .01 level

*** indicates significance at the .001 level

Figure 1. Impact of Extroversion, Strength of Ties and Embeddedness on Trust $(n=1022)$

\section{Discussion}

This study set out to bridge social network theory and personality theory by investigating (a) the impact of personality on network structure, and (b) the relative contribution of personality and network structure to levels of trust. As part of this investigation we examined correlations between the network characteristics of strength of ties, embeddedness, density, diversity and trust and found relationships all in directions that would be expected based on prior social network research. However, we found no differences between introverts and extroverts in 
network size and diversity, suggesting that, contrary to our hypotheses, the networks of introverts and extroverts look the same in term of these dimensions. We also found, contrary to our hypothesis, that extroverts' networks are filled with contacts who are significantly more embedded than those of introverts. There are at least two possible explanations for this finding regarding embeddedness. First, due to their personalities, over time extroverts may tend to introduce their acquaintances to each other, resulting in contacts that are more embedded than those of introverts. Second, extroverts may develop more durable, long-lasting, and therefore better-connected networks over time because they naturally invest more in maintaining the relationships.

While we found no difference between introverts and extroverts in terms of strength of ties overall, when we divided strength of ties into behavioral and affective components, differences emerged. Specifically, extroverts were found to feel significantly more intimate toward and intensely about their contacts, as evidenced by greater comfort at borrowing money and greater sadness at the prospect of the relationship ending. These findings, together with the finding that extroverts are more trusting of their contacts (discussed below), suggest that while the networks of introverts and extroverts tend to look the largely the same, they feel very different, a subtle distinction that nevertheless may have profound consequences.

Extroverts also were found to be significantly more trusting of their contacts, and most significantly, of their weak ties - those casual relationships considered so important for accessing novel information. This finding, which contradicts social network theory, suggests that extroverts do in fact have higher propensity to trust. In line with what social network theory would predict, we found that strength of ties does predict trust. However, contrary to what social network theory would predict, we found that after controlling for strength of ties, embeddedness does not predict trust. This finding suggests that the degree to which a contact is embedded in an informal support network has no direct effect on the level of trust that an individual extends to that contact.

There are several possible explanations for embeddedness' apparent lack of impact on trust. First, it is possible that there really is an effect, but that we were unable to capture it because the effect occurs early in a relationship before trust has been established and cemented. A second possibility is that institutional factors such as a shared work environment or school context, which can serve to boost trust (see McGrath et al., 2003), are substituting for the role of embeddedness. Third, embeddedness' lack of a role may be due to the fact that we captured personal, or "ego" networks (i.e., the individual and his/her direct contacts) rather than the whole network (i.e., the entire pattern of relationships that exist among a group of people with whom the respondent is a member). Individuals listed in an ego network, especially in the context of advice-sharing, would presumably already be trusted by the respondent to some degree, further reducing the benefit of embeddedness. Contrary to our prediction, we found no interaction effect between extrovert personality and embeddedness - embeddedness is no more important for introverts than for extroverts in terms of building trust.

In sum, we found that (a) extrovert personality has relatively little impact on network structure, although it does affect how individuals feel toward their contacts; (b) certain aspects of network structure (strength of ties) predict trust while others (embeddedness) do not; and (c) contrary to what social network theory would indicate, extroversion predicts trust. These findings help provide initial guidance for bridging the gap between the disparate frameworks of personality and social network theory, and suggest that social network theory's predominant "structural perspective" may be unnecessarily limiting. 
The overall finding that extroverts care more about and are more trusting of their contacts likely yields significant advantages from a managerial or organizational behavior point of view. First, feelings of intimacy and intensity imply an emotional investment in a contact, which in turn facilitates self-disclosure. Since self-disclosure tends to be reciprocated, this opens channels of communication and provides added opportunities for the exchange of valuable advice, information, or support. Second, the extension of trust enables extroverts to win at a numbers game. Assuming the extension of trust unlocks information and goodwill, the more people one trusts, the higher the payback: information flows more freely and more advice and support are offered, increasing the potential yield of useful information. Third, by extending more trust to their weak ties, extroverts are also winning in terms of efficiency. Spending time with and talking to people can be costly or taxing from an organizational behavior point of view. Thus, being able to reap the same levels of trust for relatively less investment of time and energy is a more costeffective strategy. And fourth, because extroverts are more trusting, they might actually use or mine their networks more extensively than introverts, further increasing the potential yield of useful information, advice and support. Altogether, by extending greater trust and affect toward their contacts, extroverts may be getting more "bang for the buck" from their relationships.

Of course, over-extending affect and trust may have drawbacks. Extroverts may be more vulnerable to risk than introverts, as not everyone in an extrovert's network likely has the extrovert's best interests at heart. For example, sharing one's weaknesses with a colleague could backfire when that colleague is asked to evaluate the individual as part of a 360-degree evaluation. This risk is compounded by the fact that the trust extended by extroverts is likely a function of the extrovert (the trustor) and not the contact (the trustee). In other words, it is unlikely that the members in an extrovert's network are really more trustworthy than those in the introvert's network; rather, they are just perceived to be by the extrovert. The sense of optimism inherent in extroverts may therefore create an unrealistic picture of a trustee's actual trustworthiness, whereas the cautiousness inherent in introverts may lead them to make a more prudent, valid assessment. Avoiding the additional risk, therefore, would require that extroverts possess the ability to distinguish and separate the trustworthy contacts from the untrustworthy ones. Therefore, future empirical studies should be conducted to determine whether extroverts' tendency to extend greater levels of trust in their informal support networks actually result in measurable liabilities or professional benefits and performance advantages.

Assuming there are benefits associated with extroversion, what are the implications for introverts? How can they gain the same benefits, if they so wish? One possible answer is to simply accommodate rather than attempt to override their introversion. Research by Marshall (1971) suggests that if introverts have access to the solitude they need (e.g., private time, time for reflection), they will enjoy the company of others to a greater degree. According to Myers \& McCaulley (1985:221), "Laypeople sometimes interpret introversion... as being associated with a dislike of or a lack of need for people. The data are more consistent with the idea that introverts...enjoy the company of others, so long as they have their needed privacy, or are not under great stress."

Another possibility is that introverts may naturally become more extroverted over time. At first glance, the chances of this possibility would appear to be slim, since researchers have suggested that personality changes minimally if at all during adulthood (McCrae et al., 2000), and because of all personality traits, extroversion has been found to change the least over time (Roberts et al., 2003a). This possibility becomes conceivable, however, when extroversion is viewed as a combination of two factors: dominance and sociability. Some research suggests that 
while traits associated with sociability such as positive affect, gregariousness, and energy level decrease after young adulthood, traits associated with dominance (e.g., independence, selfconfidence, assertiveness) continue to increase from adolescence through early middle age (Helson et al., 2002; Roberts et al., 2003b). Thus, while introverts may not see increases in their levels of gregariousness, their levels of confidence and assertiveness may increase over time, making it easier for introverts to reach out to others.

A final possibility is for introverts to intentionally override their personality and modify their behaviors. This notion underlies Cross' et al. (2002) assertion that those wishing to bolster their networks should focus less on personality and more on the network-building behaviors. They assert that, "Network patterns... are a product of intentional behaviors rather than entrenched personality characteristics - and, in contrast to personality traits, behaviors can be taught or encouraged" (Cross et al., 2002:73). For example, a shy individual can learn the social skills required to interact with others, and a quick-tempered individual can learn anger management skills that make it easier to advance in his/her professional position. Such strategies may pay off handsomely, especially since some research suggests that simply acting extroverted is as beneficial as being extroverted. For example, Fleeson, Malanos and Archille (2002) found that students who were instructed to act bold, talkative, energetic, active, assertive, and adventurous experienced a significant increase in positive affect compared to those who were instructed to act reserved, quiet, lethargic, passive, compliant, and unadventurous. They concluded that, "In regard to positive affect, there may be nothing special about being extroverted that one cannot gain simply by acting extroverted" (Fleeson et al., 2002: p. 1418).

While this study is an important foray into the intersection of personality and social network theory, it has certain limitations which should be addressed by future research. First, the study was based on students in a university setting. While students were considered suitable proxies for organizational members as discussed earlier, we realize that they naturally differ from organizational members in terms of age, motivation, and experience, which may affect our findings. In addition, the university may allow greater freedom for informal social network interactions compared to many organizations that increasingly impose greater rules and procedures that restrict informal social networking. Therefore, future related research should be carried out in other organizational contexts involving older and more experienced adults.

Second, while this study considers extroversion, measured as a dichotomous variable, future research examining personality-network structure interaction should be broadened to include other major personality constructs, allowing for greater measurement discrimination using continuous variables. The measurement of other personality variables, such as those within the "Big Five" framework would allow us to examine the impact and mediating effect of additional personality traits (e.g., agreeableness, conscientiousness, neuroticism, openness to experience) on social network structure and trust. The role of agreeableness, in particular, would be important to examine since highly agreeable individuals have been described as demonstrating such trust and relationship-facilitative behaviors as flexibility, courtesy, and tolerance (Costa \& McCrae, 1992). The personality construct of neuroticism might also have an augmenting interactive effect with extroversion that should be explored (Lynn \& Steel, 2006). It is conceivable, for example, that an extrovert who is low in agreeableness or high in neuroticism may extend less trust to his/her contacts than one who is high in agreeableness and low in neuroticism. Finally, this study did not include a measure of intentionality, which could also mediate the effect of personality and would therefore be a potentially fruitful addition to future studies. 


\section{References}

Abdulkadiroglu, A., \& Bagwell. K. (2013). Trust, reciprocity, and favors in cooperative relationships. American Economic Journal of Microeconomics, 5(2), 213-259.

Aharony, N. (2013). Facebook use by library and information science students." Aslib Proceedings, 65(1), 19-39.

Anderson, C., John, O., Keltner, D., \& Krigg, A. (2001). Who attains social status? Effects of personality and physical attractiveness in social groups. Journal of Personality and Social Psychology, 81, 116-32.

Asendorpf, J., \& Wilpers, S. (1998). Personality effects on social relationships. Journal of Personality and Social Psychology, 74(6), 1531-1544.

Baber, A., \& Waymon, L. (2007). Make your contacts count: Networking know-how for business and career success. New York: AMACOM.

Baker, W. (1993). Networking smart: How to build relationships for personal and organizational success. New York: McGraw Hill.

Barber, B. (1983). The logic and limits of trust. New Brunswick: Rutgers University Press.

Belsky, J., Jaffee, S., Caspi, A., Moffitt, T., \& Silva, P. (2003). Intergenerational relationships in young adulthood and their life course, mental health and personality correlates. Journal of Family Psychology, 73, 1015-50.

Berardo, R. (2009). Processing complexity in networks: A study of informal collaboration and its effect on organizational success. Policy Studies Journal, 37(3), 521-39.

Blau, P. M. (1993). Multilevel structural analysis. Social Networks, 15, 201-215.

Bradley-geist, J., \& Landis, R. (2012). Homogeneity of personality in occupations and organizations: A comparison of alternative statistical tests. Journal of Business and Psychology, 27(2), 149-159.

Bruch, M., Gorsky, J., Collins, T., \& Berger, P. (1989). Shyness and sociability reexamined: A multicomponent analysis. Journal of Personality and Social Psychology, 57, 904-915.

Bruning, N., Sonpar, K., \& Wang, X. (2012). Host-country national networks and expatriate effectiveness: A mixed-methods study. Journal of International Business Studies, 43(4), 444-450.

Burt, R. S. (1986). Comment. In S. Lindberg, J. S. Coleman, \& S. Novak (Eds.), Approaches to social theory (pp 105-107). New York: Russell Sage.

Burt, R. S. (1992). Structural holes: The social structure of competition. Cambridge, MA: Harvard University Press.

Burt, R. S. (2004). Structural holes and good ideas. American Journal of Sociology, 110, 349399.

Burt, R. S., Jannota, J. E., \& Mahoney, J. T. (1998). Personality correlates of structural holes. Social Networks, 20, 63-87.

Buskens, V. (1998). The social structure of trust. Social Networks, 20, 265-289.

Chan, Y., \& Lee, R. (2006). Network size, social support and happiness in later life: A comparative study of Beijing and Hong Kong. Journal of Happiness Studies, 7(1), 87112.

Chang, J., \& Cheng, C. (2013). Effects of school team embeddedness on team trust and potency. Quality and Quantity, 47(4), 1851-68.

Cheek, J., \& Buss, A. (1981). Shyness and sociability. Journal of Personality and Social Psychology, 41, 330-339. 
Cohen, S., Brissette, I., Skoner, D., \& Doyle, W. (2000). Social integration and health: The case of the common cold. Journal of Social Structure, 1(3).

Coleman, J. (1994). Foundations of social theory. Cambridge, MA: Belknap Press.

Costa, P., \& McCrae, R. (1992). NEO PI-R professional manual. Odessa, FL: Psychological Assessment Resources.

Covey, S. (2006). The speed of trust: The one thing that changes everything. New York: Simon and Schuster.

Cross, R., Nohria, N., \& Parker, A. (2002). Six myths about informal networks - and how to overcome them. Sloan Management Review, 43, 67-75.

Dobrow, S. R., Chandler, D. E., Murphy, W. M., \& Kram, K. E. (2012). A review of developmental networks: Incorporating a mutuality perspective. Journal of Management, 38(1), 210-242.

Emirbayer, M., \& Goodwin, J. (1994). Network analysis, culture, and the problem of agency. American Journal of Sociology, 99, 1411-1454.

Fleeson, W., Malanos, A., \& Archille, N. (2002). An intraindividual process approach to the relationship between extroversion and positive affect: Is acting extroverted as "good" as being extroverted?. Journal of Personality and Social Psychology, 83, 1409-1422.

Fu, W., Diez, J. R., \& Schiller, D. (2013). Interactive learning, informal networks and innovation: Evidence from electronics firm survey in the Pearl River Delta, China. Research Policy 42(3), 635-646.

Granovetter, M. (1973). The strength of weak ties. American Journal of Sociology, 78, 13601380.

Granovetter, M. (1992). Economic action and social structure: The problem of embeddedness. In M. Granovetter \& R. Swedberg (Eds.), The Sociology of Economic Life (pp. 53-81). Boulder, CO: Westview Press.

Granovetter, M. (1995). Getting a job: A study of contacts and careers. (2 ${ }^{\text {nd }}$ ed.). Chicago: University of Chicago Press.

Gulati, R. (1995). Does familiarity breed trust? The implications of repeated ties for contractual choice in alliances. Academy of Management Journal, 38(1), 85-112.

Hardin, R. (1996). Trustworthiness. Ethics, 107, 26-42.

Hawkins, R., \& Maurer, K. (2012). Unraveling social capital: Disentangling a concept for social work. British Journal of Social Work, 42(2), 353-370.

Helson, R., Jones, C., \& Kwan, V. (2000). Personality change over 40 years of adulthood: Hierarchical linear modeling of two longitudinal samples. Journal of Personality and Social Psychology, 83, 752-766.

Huang, T., Chi, S., \& Lawler, J. S. (2005). The relationship between expatriates' personality traits and their adjustment to international assignments. The International Journal of Human Resource Management, 16(9), 1656-1670.

Jensen-Campbell, L., Adams, R., Perry, D., Workman, K., Furdella, J., \& Egan, S. (2002). Agreeableness, extraversion, and peer relations in early adolescence: Winning friends and deflecting aggression. Journal of Research in Personality, 36, 224-51.

John, O. (1990). The "Big Five" factor taxonomy: Dimensions of personality in the natural language and in questionnaires. In L. A. Pervin (Ed.), Handbook of Personality: Theory and Research, (pp. 66-100). New York: Guilford Press. 
Johnson, J. (2005). The IPIP-NEO (International Personality Item Pool Representation of the NEO PI-R). http://www.personal.psu.edu/faculty/j/5/j5j/IPIP/. Accessed September 13, 2005.

Klein, K., Lim, B., Saltz, J., \& Mayer, D. (2004). How do they get there? An examination of the antecedents of centrality in team networks. Academy of Management Journal, 47, 952963.

Kroeger, O., \& Thuesen, J. (1988). Type talk. New York: Delacorte Press.

Kuo, T. (2013). How expected benefit and trust influence knowledge sharing. Industrial Management + Data Systems, 113(4), 506-522.

Leung, W.O., Xin, L., Priem, R., \& Shaffer, M. (2013). Top management team trust, behavioral integration and the performance of international joint ventures. Journal of Asia Business Studies, 7(2), 99 -122.

Luhmann, N. (1979). Trust and power. New York: Wiley.

Lynn, M., \& Steel, P. (2006). National differences in subjective well-being: The interactive effects of extraversion and neuroticism. Journal of Happiness Studies, 7(2), 155-165.

Marshall, N. J. (1971). Orientations toward privacy: Environmental and personal components. Doctoral dissertation, University of California. Dissertation Abstracts International, 31 , 4315B. (University Microfilms No. 71-815).

Mayer, R., Davis, J., \& Schoorman, F. (1995). An integrative model of organizational trust. Academy of Management Review, 20(3), 709-734.

McCrae, R. R., Costa, P. T. Jr., Ostendorf, F., Angleitner, A., Hrebiackova, M., Avia, M. D., Sanz, J., Sanchez-Bernardos, M. L., Kusdil, M. E., Woodfield, R., Saunders, P. R., \& Smith, P. B. (2000). Nature over nurture: Temperament, personality, and life span development. Journal of Personality and Social Psychology, 78, 173-186.

McGrath, C., \& Zell, D. (2009). Profiles of trust: Who to turn to, and for what." MIT Sloan Management Review , 50(2), 75-80.

McGrath, C., Vance, C., \& Gray, E. (2003). With a little help from their friends: Exploring the advice networks of software entrepreneurs. Creativity and Innovation Management, 12, $2-10$.

McGuire, W. J. (1968). Personality and susceptibility to social influence. In E. F. Borgatta \& W. W. Lambert (Eds.), Handbook of personality theory and research, (pp. 1130-1187). Chicago: Rand McNally.

McPherson, J. M., Popielarez, P. A., \& Drobnic, S. (1992). Social networks and organizational dynamics", American Sociological Review, 57, 153-170.

McPherson, M., Smith-Lovin, L., \& Cook, J. (2001). Birds of a feather: Homophily in social networks. Annual Review of Sociology, 27, 415-44.

Mehra, M., Kilduff, M., \& Brass, D. (2001). The social networks of high and low self-monitors: Implications for workplace performance. Administrative Science Quarterly, 46, 121-146.

Myers, I., \& McCaulley, M. (1985). A guide to the development and use of the Myers-Briggs Type Indicator. Palo Alto: Consulting Psychologists Press.

Myers, I., \& Myers, P. (1980). Gifts differing. Palo Alto, CA: Consulting Psychologists Press.

Obstfeld, D. (2005). Social networks, the tertius iungens orientation and involvement in innovation. Administrative Science Quarterly, 50, 100-130.

Ozer, D., \& Benet-Martinez, V. (2006). Personality and the prediction of consequential outcomes. Annual Review of Psychology, 57, 401-421. 
Paunonen, S. (2003). Big five factors of personality and replicated predictions of behavior. Journal of Personality and Social Psychology, 84, 411-22.

Pervin, L., \& John, O. (1999). Handbook of personality: Theory and research (3rd. Ed.). New York, London: The Guilford Press.

Pfeffer, J. (1991). Organization theory and the structural perspective on management. Journal of Management, 17, 789-803.

Putnam, R. (1995). Bowling alone: America's declining social capital. Journal of Democracy, 6(1), 65-78.

Roberts, B., Robins, R., Caspi, A., \& Trzesniewski, K. (2003). Personality trait development in adulthood. In J. L. Mortimer \& M. Shanahan (Eds.), Handbook of the Life Course (pp. 579-598). New York: Kluwer Academic.

Roberts, B., Caspi, A., \& Moffitt, T. (2003). Work experiences and personality development in young adulthood. Journal of Personality and Social Psychology, 84, 582-93.

Roberts, B., Walton, K., \& Viechtbauer, W. (2006). Patterns of mean-level change in personality traits across the life course: A meta-analysis of longitudinal studies. Psychological Bulletin, 132(1), 1-25.

Rotter, J. B. (1967). A new scale for the measurement of interpersonal trust. Journal of Personality, 35, 651-665.

Rousseau, D., Sitkin, S., Burt, R., \& Camerer, C. (1998). Not so different after all: A cross disciplinary view of trust. Academy of Management Review, 23, 1-12.

Salavisa, I., Sousa, C., \& Fontes, M. (2012). Topologies of innovation networks in knowledgeintensive sectors: Sectoral differences in the access to knowledge and complementary assets through formal and informal ties. Technovation, 32(6), 380-399.

Singh, R. P., Hybels, R. C., \& Hills, G. E. (2000). Examining the role of social network size and structural holes. New England Journal of Entrepreneurship, 3(2), 47-58.

Stewart, G. L., \& Barrick, M. R. (2000). Team structure and performance: Assessing the mediating role of intrateam process and the moderating role of task type. The Academy of Management Journal, 43, 135-148.

Swickert, R. J., Hittner, J. B., \& Foster, A. (2010). Big Five traits interact to predict perceived social support. Personality and Individual Differences, 48, 736-741.

Swickert, R. J., Rosentreter, C.J., Hittner, J. B., \& Mushrush, J. E. (2002). Extraversion, social support processes, and stress. Personality and Individual Differences, 32(5), 877-91.

Turkina, E., \& Thai, M. T. T. (2013). Social capital, networks, trust and immigrant entrepreneurship: A cross-country analysis. Journal of Enterprising Communities, 7(2), 108-124.

Uzzi, B. (1997). Social structure and competition in interfirm networks: The paradox of embeddedness. Administrative Science Quarterly, 42, 35-67.

Wellman, B., \& Wortley, S. (1990). Different strokes from different folks: Community ties and social support. American Journal of Sociology, 96, 558-88.

Zarafshani, K., \& Rajabi, S. (2011). Effects of personality traits on entrepreneurial intentions: An empirical study in Iran. International Journal of Management, 28(3), 630-41.

Zolin, R., Hinds, P. J., Fruchter, R., \& Levitt, R. E. (2004). Interpersonal trust in crossfunctional, geographically distributed work: A longitudinal study. Information and organization 14(1), 1-24. 